\title{
On Regulation of Celebrity Endorsement in China
}

\author{
Mingqian Li \\ Postgraduate School, East China University of Political Science and Law \\ Shanghai 200042, China \\ E-mail:1mq406@hotmail.com
}

\begin{abstract}
Advertisers have attempted to quantify the use of celebrities with the aim of evaluating their influence on the consumer. However, sometimes celebrities who engage in false or deceptive advertising are very likely to mislead consumers which may cause harm to consumers in terms of property loss and personal damage. Due to celebrity endorsements being highly visible to the public, the solution to this issue is of significant relevance to consumers and the general public. Therefore, advanced experience on celebrity endorsement should be drawn from abroad, and a clear assignment of obligation standard is highly desirable.
\end{abstract}

Keywords: Celebrity Endorsement, False Advertising, Fault Liability, Joint Legal Obligation

\section{Preliminary Consideration}

\subsection{Basic Aspects of Celebrity Endorsement}

Celebrity endorsements are nothing new to marketing campaign. The use of celebrities in advertisements has been a standard commercial technique and a prominent procedure aimed at promoting new products, enhancing market share for existing brands, and finding new ways to communicate with their consumers. For example, in 1996 alone, companies invested more than $\$ 1$ billion in athletic endorsement deals and approximately $\$ 10$ billion more to advertise and promote these celebrity endorsements. And the percentage of advertisement worldwide featuring a celebrity is still increasing, because of the common recognition that celebrities have a powerful effect on the affluence of the products they endorse.

Since the endorser has been defined as "any individual who enjoys public recognition and who uses this recognition on behalf of a consumer good by appearing with it in an advertisement", the primary purpose of celebrity endorsement is for the advertiser to make use of consumers' trust in celebrities, who may be actors, sports personalities, experts or other public figures. They provide the consumers with a shortcut when shopping for something that may not be familiar to them. However, this kind of reliance on celebrity's good faith is a substantive basis for the endorser's legal liability if the advertisement is false or deceptive.

In this regard, I would like to start by outlining an informational background and then provide a description of the problems in which both the celebrity endorsers and consumers encounter. Then, I will examine and analyse the related national legislation and regulations. This leads onto observations of overseas practices. Accordingly, some suggestions will be put forward to maintain the positive aspect of celebrity endorsements as well as diminish, or even eliminate, its negative impacts.

\subsection{Cases Due to Celebrity Endorsement in China}

With the fast development of media technology and rapid growth of the economy in the last two decades, celebrity endorsements are widely used in advertising in China. There have been many Chinese advertisements featuring celebrities, however, problems quickly followed.

\subsubsection{Sanlu Melamine Mile Powder Scandal}

In 2007, the Sanlu melamine milk powder scandal shocked people home and abroad. A very popular actress Deng Jie was the endorser, and she said in the advertisement, "I am always picky with milk powder; but Sanlu infant milk powder is so professional. I trust it very much because of its expertise in production, good quality as well as famous brand; additionally, the price is quite reasonable, not expensive at all; I trust Sanlu milk powder." However, it turns out that the same "high quality" milk powder contained melamine which led to thousands of young families suffering.

\subsubsection{Hou Yaohua Endorsed 10 False Products}

The recent case in point is related to the once popular comedy actor Hou Yaohua. In 2009, China Advertising Association issued a notice outlining that Hou Yaohua had endorsed 10 false products, including health care food, medicines, and medical devices. As far as the other celebrities as Zhao Zhongxiang, Guo Degang, Fan Bingbing are concerned, the number of claims of false or misleading advertising are vast. Despite some victims pursuing legal 
action against the celebrities directly, and related public interests associations also challenging the celebrities' statements as deceptive advertising, the majority of the suits failed due to the lack of a related legal basis.

Concerning all these problems, there has been a heated discussion amongst scholars and practicing professionals regarding the question of how to regulate celebrity endorsement in false or deceptive advertising.

\section{The Status Quo of Related Legislation on Celebrity Endorsement}

In light of the above cases, the celebrity endorsement in false or deceptive advertising can be defined as a wrong committed by a celebrity for his or her false or misleading misrepresentation of the actual facts of the endorsed products. In General, the misrepresentation can be classified into three types: dishonest testimonials; unsubstantiated claims; and inducing expression. In order to supervise and regulate advertising endorsement, China has promulgated several regulations and legislation.

\subsection{Regulation of the Advertisement Law}

As early as 1994, Article 38 of Advertisements Law states, Where, in violation of the provisions of this Law, publication of a false and misleading advertisement affecting consumers, thereby causing an infringement and damages to their lawful rights and interests who purchase the goods or accept the service, based on civil law the advertiser shall be liable whilst the advertising agent and advertisement publisher, who have knowledge of or are deemed to have such knowledge of the falsity of the content of the advertisement, but continue to design, produce and publish it, shall be jointly liable according to law with the advertiser. A social organization or other organizations, which recommend goods or services to consumers in a false and misleading advertisement and consequently causes infringement and damage to the lawful rights and interests of consumers, shall also bear joint responsibility in law.

According this clause, it is the corporate entities that are to be punished without any consideration of the individual committing a wrong. This is one of the reasons why the victims of the Sanlu milk powder scandal failed to bring a suit against the endorser, who could not have been be subject to the law.

\subsection{Jurisdiction of State Administration of Industry and Commerce}

In 1997, the State Administration of Industry and Commerce issued a code of advertising ethics. The second clause stipulates that advertising ethics is the moral baseline for all advertising. In addition, the norm applies to all entities involved in advertising, whether they are corporate identities or individuals. And it applied to all the advertisement participants, including unit and individual who normally would be the spokesman. That is to say, the State Administration of Industry and Commerce is entitled to deal with endorsers who breach the advertising ethics by intentional misrepresentation, deceptive statement or otherwise. Nevertheless, this is only a principle, aiming at setting a moral standard for producers and individuals involved to achieve. Having characteristics similar to a policy or guideline it is not easy to be implemented and enforced.

\subsection{Recent Legislation and Rules}

As a matter of fact, with the increasing problems involved with irresponsible celebrity endorsement, there has been increasing agreement on the notion that developing a set of policies to regulate the activities of celebrities in advertising is highly desirable. Also, greater attention has been attached to drafting new laws or altering to some extent corresponding legislation and rules in order to make them apply to endorsers as well.

A case in point is the recent published Food Safety Law. According to the fifth provision, any organization, whether individual, social or corporate which actively participate in the false or misleading advertising of food products will bear equal responsibility if consumer's legitimate interests are harmed. On that account, when guilty of engaging in the false advertising of food, the celebrity endorser may bear equal responsibility as food producers under the condition that the endorsed food caused harm to consumers. The victim consumers can either claim to the production enterprises, or directly demand compensation from the celebrity who has recommended the food.

It is said that this is the first time China has expressed an idea of punishing the endorsers with joint responsibility. Obviously, the aim of such a clause is to burden celebrities with greater social responsibility when endorsing. Considering being held responsible for the endorsed food quality and the serious consequences arising therefrom, the celebrities are supposed to pay more attention to the quality of the product they are endorsing, and hence protect the consumers' interests.

Still, in practice there is some difficulties as to how to define "false or misleading advertising", which is the precondition of holding endorsers to account. Since there is no explicit expression of "false or misleading advertising" in Advertisement Law, but usually is defined on the basis of the Statement issued by State Administration of Industry and Commerce on recognition of false or misleading advertising, it can quite easily result 
in inconsistencies for the judicial department. This is especially true when the victim consumers try to bring litigation against endorsers.

Despite that, it cannot be denied that there is an increasing effort to deal with irresponsible celebrity endorsement. On February 16, 2009, five national ministries, including the State Administration of Radio Film and Television of China, State Administration of Industry and Commerce, Ministry of Health, jointly issued a circular, banning actors and social celebrities from hosting nutritional, medical and health care media programs. Three months later, the Top 10 severely unlawful advertisement was chosen and made public by State Administration of Industry and Commerce after finishing the first quarterly examination.

\section{The Way to Allocate Obligation}

From the point of view of jurisprudence, where there is no duty, there is no right. Anybody gaining interests from exercising rights has to fulfil their duties. Celebrities are able to make considerable profit and public exposure through endorsing products. Therefore, they bear the corresponding burden that cannot be shaken off. In breach of obligation, the top choice, without any doubt, should be ascribed to tortious liability, whose primary purpose is to require the wrongdoer or the party at fault to compensate a victim for the injury incurred. In this way can the individual consumer be able to redress any wrongs committed by the celebrity. At the heart of discussion is the way to distribute the duties and attribute the obligations when it comes to bear torious liability.

\subsection{Argument for Fault Liability}

There are some scholars who argue the application of liability based on fault should be adopted. In other words, whether the celebrity can be held accountable depends on the existence of their fault in the endorsement. If they have already paid reasonable care and performed the basic duty in qualifying endorsed products, but still cannot acquire knowledge that the products are falsely advertised, they should be free from their legal obligation. On the other hand, after knowing that the products do not meet the relevant requirements, if the celebrity were to endorse a false or misleading product, they may be accused of fraud and shall bear legal responsibility.

\subsection{Proposal of Joint Legal Obligation}

Nevertheless there are scholars who argue that the celebrity endorser shall bear joint responsibility if endorsing a false or misleading product, just as what the Food Safety Law has sought to do. That is to say, the application of joint legal obligation of celebrity endorsement should expand from food advertising to all products in order to better regulate celebrity endorsement. To frame it differently, the celebrity, as long as engaged in false or misleading advertising leaving consumers potentially harming consumer's rights, should be jointly and severally liable. Indeed, this opinion has already gained some response by both the government and the legislatures. For example, Hubei Province, recently formulated the "Hubei Drugs Management Act," which states that "social groups or other organizations, individuals shall be jointly and severally liable for recommending drugs to consumers in false advertising and thus consumers' legitimate rights being infringed." This is the first step of expanding celebrities' obligation from food advertisements to drug advertisements.

\subsection{Reasoning Rested on Both Sides}

Both of the above views have their merits. It is accepted that the celebrity endorser should pay due care to the endorsed product, food or otherwise, based on the principle of good faith. Also, under the circumstances of ignoring product quality or gross negligence, the celebrity should be answerable for damages caused by the endorsed product. However, I am not a believer in the argument that the celebrity should always bear a joint legal obligation in the context of false advertising. A one-size-fits-all solution does not take into consideration all the facts. Generally, there are two main situations to take into account.

In the first situation where the celebrity has reason to suspect the product to be endorsed will be falsely or misleadingly advertised yet continues to deceive consumers, the assumption of joint legal obligation is agreed.

The second situation is when the endorsers do not know they are engaging in false adverting. However, as to how to define such a situation, it will require greater attention. As it has been mentioned earlier, the recognition of false advertising is based on a Statement. By virtue of the Statement, two aspects are to be investigated; the advertisement itself as well as the product being advertised (for instance whether the product meets relevant standards, the degree of effectiveness, the use of registered trademarks, and the awards record). Any instance where the advertisement falsely or misleads the viewer of the facts is recognized as false advertising. Therefore, false advertising can be divided into two types: one is that the product itself is false, and the other is that the advertisement exaggerates a detail to the point of being misleading. 
In this context, the burden of the celebrity's responsibility is the prudent formal examination on the product's qualification and reasonable care of checking the related warranty and certificates issued by relevant governmental departments or authorized institutions. Failure to perform this type of duties will lead to corresponding legal liability on the basis of extent or degree of fault. Whilst, as long as the celebrity has performed his or her due responsibilities, they would be free of legal obligation.

That is to say, the celebrity is not accountable for a thorough and detailed examination which should belong to the government's responsibility. The product's producer is the one to guarantee the quality and the same is true for the related governmental institution. In this regard, the celebrity neither has obligation or ability to handle the substantive examination on the products. To argue otherwise would be breach of fairness, which is the foundation of law.

At the same time, considering that the social status of celebrities is stronger than normal consumers, who might become a victim from the product's misrepresentation, some limitations should be added to the fault liability, which takes into account the ability of proof by potential victims.

Generally speaking, when the fault liability principle is applied, the plaintiff must prove his case against the defendant by presenting evidence. However, in the case of celebrity endorsement, it should be the celebrities that bear the burden of proof not the victim consumers. If endorsers cannot convincingly prove they have already exercised due care as mentioned above they will assume the risk of losing the lawsuit. With distribute the burden of proof to celebrities, on one hand, they will be more cautious and prudential with endorsement in the future, on the other hand, the consumers legitimate interests will be better protected, which will better manifest the fairness and justice of the law.

\section{Observation of Overseas Practices}

Modern celebrity endorsement in advertisements has its origin in USA and it has crossed the boundaries to other countries around the globe, including South Korea, Japan, and European countries. From years of regulating endorsements they have developed a rich experience to prevent celebrities endorsing false advertisement, which affords us good models that merit attention.

\subsection{USA Regulation}

In USA, endorsements are subject to the regulation and oversight of the Federal Trade Commission (FTC). Section 12 of the Federal Trade Commission Act addresses specifically unlawful endorsements and false advertisements. Besides this, the FTC has drawn up a Guideline to clarify the detailed criteria which the endorsements have to meet. For example, "If the advertisement claims the celebrity uses the product or service, the celebrity must in fact be a bona fide user, and the advertiser can only use the endorsement so long as it has a good faith belief that the celebrity continues to hold the views expressed in the advertisement."

On December 1, 2009, FTC revised the Guidelines with special attention on celebrity endorsements. It formulated more detailed rules and regulations on the judgment of whether an advertisement is "false and deceptive" or misleads potential consumers. Testimonial advertisements where the celebrities could not prove with competent and reliable evidence are banned. In additional, specific examples were also provided to help with identification or evaluation of the endorsement. With these numerous examples, the judicial department as well as normal citizens can have better understanding and be more informed.

\subsection{Other Observations}

Japan has been experiencing a booming advertising industry and celebrity endorsement in advertisement is extremely popular where $70 \%$ of all advertisements feature famous people. Meanwhile, with the development of entertainment industry and the popularity of its dramas, movies, music, Korea is one of many consumerist countries which frequently have advertisements endorsed by celebrities. Their experience with coping with endorsed false advertisement can provide valuable insights.

In Japan, having been found guilty of endorsed false endorsements, the celebrity is pressured to publically apologize, thereby ruining their reputation and thus have employment opportunities greatly diminished. As such, celebrities seldom engage in medical advertisement, and they would not commit to the product's quality or its effectiveness, medical or otherwise.

In Korea, the disputes about celebrity endorsement of false advertisements happen rarely, thanks to their Advertising Self-regulation Institution, which has done an effective job in previewing the endorsed advertisement. It has developed a series of rules, imposing strict limitation on products which to be advertised in terms of ways to express, audience difference, and other related aspects. Take drugs for instance, the Institution divided drugs into general 
medicine, special-function medicine and medicinal material. The weight-loss pill has been identified as special-function medicine, which was prohibited to be TV advertised, and the same is for medicinal material. As to general medicine, it is also not allowed to use any inducing testimonials. Any violation shall be severely punished.

\section{Suggestions}

Celebrities ascribe their names, their public image, their popularity as well as their credibility to a host of products such as food and daily care consumables. Many occasions, these product endorsements can not only win customers' preference, promote sales, but also earn the celebrity substantial sums of money, frequently more than their normal working pay. The problem arises when the celebrity is irresponsible in ensuring the endorsed product is being advertised with a fair and balanced view. Cases of consumers suffering from unsubstantial statements came forth one after another. The reasons why some celebrities stray from their responsibilities to consumers and society can be attributed to the enormous gains the celebrity stands to gain without relevant duties caused by defective legislation and rules, inadequate supervision and lack of self-discipline and legal awareness.

After summarizing and analyzing the overseas experiences of coping with false celebrity endorsements, some strategic suggestions will be proposed on the basis of the national conditions of our country as follows.

\subsection{More Specific Legislation and Regulation}

A more specific and detailed regulation should be laid down, and a clear assignment of obligation standard should be provided in order to make every advertising participants, including advertisers, advertising agents, advertisement publishers as well as the celebrity endorsers, observe the law, abide by basic marketing ethics, promote social culture.

This is what we should learn from America. Just as the FTC in America has done, numerous detailed rules and specific examples have been established. This will greatly facilitate the tackling of misleading statements in false endorsement. Hence, where there is a breach of obligation regulated by law, there is a punishment. Punishment is justice for the unjust. It would provide better protection for the consumers because once a causal relationship between the damage of consumers and celebrities' misrepresentation of endorsed products is established, the celebrities would be held liable for the losses caused by their irresponsible activity, unless they could prove that reasonable care has been paid and that they are not at fault. Also, with the clear regulation of relevant laws and regulations, different government departments can make up for deficiencies of each other.

\subsection{Strengthen Supervision from Government}

Strengthening of supervision, enforcement and increasing penalties are also greatly needed. A good regulatory environment is of vital importance to prevent false or deceptive advertising. For instance, advertisement involving celebrities could be examined on its content by related institutions before publishing it to the public, whilst a broadcaster which releases such an advertisement without prior examination will be subject to sanctions. At this point, Korea has set a good example which would be beneficial to regulation of celebrity endorsement.

In most cases there is a failure to abide by regulation, and lax enforcement of the rules. In order to cope with this, the government should not only strengthen supervision on advertising activity, but also make every effort to create conditions in which both the celebrities and producers hesitate to endorse misleading advertisements. For example, the sum of penalties for engaging in false advertising should be raised. Only when the producers realize the high costs of making deceptive advertisements can they stop publishing false advertisements. Nevertheless, the focus on attacking celebrity endorsement for false or deceptive advertisements does not mean the relevant government departments absolve their responsibilities of supervision, examination, and management. Compared to celebrities, the government has more resources available to identify false advertising products.

\subsection{Stronger Corporate Social Responsibility}

The advertiser should bear in mind its corporate social responsibility. Corporate social responsibility is an increasingly important part of the business environment. The past twenty years have seen a radical change in the relationship between business and society. Companies have experienced changes in terms of the increasing size and the gradual significant influence of society. It is a special obligation for companies to not only pursue profit, but also take into consideration the maintenance and the promotion of the social interest.

Companies that heavily rely on endorsements to increase sales whilst ignoring the product's quality cannot have stable long term growth. In this regard, the celebrity endorsed advertisements should be based on illustrating the product's values in the best possible way but not on using the celebrity's reputation to mask the product's shortcomings. Moreover, once the product causes any infringement on consumers, there will be an inescapable liability. With stronger social responsibility, the related participants such as the advertisers, advertising agents and 
advertisement publishers will pay more attention to product quality, not only on short term profit. Additionally, they will also be careful with using celebrity endorsement for their products as it has a greater social responsibility.

\subsection{Self-Cautious and self-discipline of Celebrities}

The endorsers themselves should be more cautious and pay more attention whenever asked to make statements in advertisements and other media programs. Many celebrities in advertisement do role-playing according to the director's instructions, without considering their moral duty and legal obligation. Such an endorsement, where the celebrity is akin to an empty jar or a stringed puppet, may well mislead consumers who unwittingly trust the celebrity's good faith and sound judgement. Also, the profits made from advertisement may skew the celebrity's sense of moral obligation. In this regard, a strong sense of social responsibility and a clear sense of self-discipline are highly desirable. The false advertisement is the infringement of the legitimate rights and interests of consumers, as well as the advertiser's competition. While it is true that maximum economic benefits certainly should be pursued, something that is determined by the market; the public interest must be taken into account as well, thereby legitimising the accrued benefits. In the context of the celebrity endorsement, the celebrity should always exercise self-control and maintain personal integrity and, more importantly, foster stronger legal awareness.

\section{References}

Lane \& Randall. (1996). Nice Guys Finish First. Forbes, 158, 236-237.

McCracken. (1989). Who is the Celebrity Endorser? Cultural Foundations of the Endorsement Process, 16, 311.

Kilburn, D. (1998).Star Power. Adweek, 39, 20-21.

Li Juan. (2009). Legal Regulation on False Advertising. Journal of Shan Xi Police Academy, 17, 43.

Money, R.B., Shimp, T.A., \& Sakano, T. (2006). Celebrity Endorsement in Japan and the United States: Is Negative Information All the Harmful? Journal of Advertising Research, 3,113-123.

Anita M. Moorman. (2006). False Advertising and Celebrity Endorsements: Where's My Script? Sport Marketing Quarterly, 15, 111-113.

Meng Xiaoyang. (2009). Commenting on the Sanlu Milk Powder Incident and Article 55 of the Food Safey Law. Hebei Law Review, 27, 4.

Zhao Bingliang. (2003). Korean Advertising Limitations and Features of Advertising Self-regulation Institution. National Advertising Conference Paper.

The Sanlu Endorsement of Denjie. [online] Available: http://news.sohu.com/20090617/n264572312.shtml(September 15, 2010).

Joint Legal Obligations are Supposed to Exert on Celebrity Endorsement. [Online] Available: http://www.sxrd.gov.cn/0/1/7/36/1017.htm (September 10, 2010).

Hubei Provincial People's Government Press Conference, [Online] Available:http://www.hubei.gov.cn/xwfbh/xwfbh2009/0924/200911/t20091113_107741.htm(September 17, 2010).

David D. Oxenford, Nancy J. Felsten, (2010), New FTC Guidelines on Endorsements and Sponsorship, National Law [Online] Review. Available: http://www.natlawreview.com/article/new-ftc-guidelines-endorsements-and-sponsorship-disclosure-broadcasters-an d-new-media-compan (September 17, 2010). 